\title{
Para una crítica de toda teología política*
}

For a critique of all political theology

\author{
YVES CHARLES ZARKA
}

Université de Paris-Sorbonne/CNRS

\begin{abstract}
RESUMEN. El vertiginoso regreso de lo teológico a lo político es uno de los acontecimientos sintomáticos de la posmodernidad en que vivimos. Sin embargo, es necesario repensar lo político sin lo teológico y articular una crítica radical de lo teológico-político. Sólo así, lo político podrá recobrar su relatividad e historicidad. Para ello, puede encontrarse en la crítica a Carl Schmitt, una vía con la que conseguir la separación de lo político y lo religioso. Vía que, aunque sea ardua, es prioritaria ya que el mundo político del mañana dependerá de su éxito o fracaso.
\end{abstract}

Palabras clave: Teología política, Carl Schmitt, Hobbes, Pascal, Rousseau.
ABSTRACT. The dizzy return of the theology to the politics is one of the symptomatic phenomena of this post - modern period we live. However, it is necessary to rethink the politics without theology and to articulate a radical critique of the theological-politics. Therefore, politics could recover their relativity and historicity. In order to address this, the critique of Carl Schmitt could be one of the strategies to get the separation between the political and the religious. In spite of the arduous of this work, it is primordial since the future politics will depend on its success or failure.

Key words: Political theology, Carl Schmitt, Hobbes, Pascal, Rousseau.

Vivimos en una época extraña, una época donde la cuestión teológico-metafísica de Dios aparece, en muchos aspectos, como algo en desuso, pero también una época en que la cuestión teológico-política de Dios está en el centro de la actualidad no sólo filosófica sino también política. La tesis de la muerte de Dios, en la que el pensamiento contemporáneo creyó encontrar uno de sus principios fundamentales, no parece haber repercutido en el terreno político. Aunque la cuestión de las pruebas de la existencia de Dios, del conocimiento de su naturaleza y de sus atributos, ahora nos remiten a un simple juego de especulación teórica o a una consideración elemental dentro del campo de la historia de las ideas, las figuras de Dios aún desempeñan un papel importante en la definición de determinadas nociones políticas como las de soberanía, gobierno, legitimación, guerra, paz, etc. Sin duda la historia de las figuras políticas de Dios a menudo ha acompañado a la historia de las figuras metafísi-

* Traducción de Tomás Onaindia. 
cas de Dios, pero parece que también la ha sobrevivido. Así, la vitalidad del concepto de Dios parece haber basculado hacia la teología política. Pero mientras al principio de la modernidad, en Hobbes y Spinoza por ejemplo, la cuestión teológico-política encubría, a través de una hermenéutica del texto bíblico, un doble propósito que pretendía en principio asegurar una hegemonía de lo político sobre lo religioso y lograr que la historia sacra basculase hacia una historia profana, en el siglo XX y a comienzos del XXI ha sido el vector de tentativas de resacralización de lo político.

Podemos tomar como indicio de esta importancia de lo teológico-político el problema de la secularización a través del cual se ha dilucidado, en la segunda mitad del siglo XX, la definición misma de los tiempos modernos. Como ya sabemos, sobre esta cuestión se enfrentaron Carl Schmitt, para el que el mundo moderno se constituyó a través de la secularización de los conceptos teológicos ${ }^{1}$, y Hans Blumenberg, para el que, por el contrario, el mundo moderno se establece a través del autoagotamiento de Dios; Blumenberg lo ve realizado, al final de su obra La legitimidad de los tiempos modernos, en el pensamiento de Giordano Bruno en particular.

\section{Para Carl Schmitt:}

«Todos los conceptos básicos de la teoría moderna del Estado son conceptos teológicos secularizados. Y esto es así no sólo en cuanto a su desarrollo histórico, porque fueron transferidos de la teología a la teoría del Estado - por ejemplo, el Dios todopoderoso se ha convertido en el legislador omnipotente-, sino también por su estructura sistemática, cuyo conocimiento es necesario para un análisis sociológico de esos conceptos. La situación excepcional tiene para la jurisprudencia el mismo significado que el milagro para la teología» ${ }^{2}$.

\section{Para Hans Blumenberg, por el contrario:}

«Sin duda la edad moderna no empezó como la época del Dios muerto sino como la época del Dios oculto, del deus absconditus - $\mathrm{y}$, desde un punto de vista pragmático, un Dios oculto equivale a un Dios muerto-. La teología nominalista se alarmó ante una relación del hombre con el mundo cuyas implicaciones se podían enunciar con el postulado: el hombre debe obrar como si Dios estuviese muerto. Esto es lo que conduce a ese inventario inquieto del mundo que podemos calificar como impulso inaugural de la edad de la ciencia» ${ }^{3}$.

${ }^{1}$ Lo mismo puede decirse de Eric Voegelin, pero desde una perspectiva totalmente distinta a la de Carl Schmitt, cf. Die politischen Religionen, 1938; The New Science of Politics. An Introduction, University of Chicago Press, 1952; Wissenschaft, Politik und Gnosis, Kösel, 1959; Faith and Political Philosophy. The Correspondence between Leo Strauss and Eric Voegelin 1934-1964, Pennsylvania State University Press, 1993.

2 Carl Schmitt, Politische Theologie, 1922, 2. ${ }^{\text {a }}$ edición 1934, reedición Berlín, Duncker und Humblot, 2004.

${ }^{3}$ Hans Blumenberg, Die Legitimität der Neuzeit, Frankfurt, Suhrkamp Verlag, 1966, 2. ${ }^{\text {a }}$ edición 1988. 
En esta oposición, lo que está en juego es el lugar de lo teológico-político $\mathrm{y}$, a través suyo, la evaluación del mundo moderno. Y, por cierto, así fue como Schmitt y Blumenberg interpretaron el envite de su oposición. En el comentario final de su segunda Teología política ${ }^{4}$, Schmitt interpreta la obra de Blumenberg como una empresa cuyo objetivo es la negación científica de toda teología política: «científica en el sentido de que se trata de un concepto científico que considera inadmisible toda prolongación y toda transposición surgidas de la doctrina de salvación de una religión que aspira a ser absoluta. Semejantes transposiciones no son, a sus ojos, más que hipotecas trágicas que datan de épocas superadas. Su liquidación definitiva va de la mano con la mundanalidad de los nuevos tiempos (Neu-Zeit) desteologizados y sigue siendo "su labor crítica absoluta"» ${ }^{5}$. Se trataría, pues, de una liquidación desteologizada por la ciencia moderna de toda teología política: «la nueva ciencia, puramente mundana y humana, es el proceso-progreso ininterrumpido de una ampliación y de una renovación del saber, confinados en lo puramente humano y mundano y provocados por una curiosidad humana sin límites». Esta liquidación científica de la teología política que Schmitt cuestiona, es la continuación de otra tentativa de liquidación, la que había emprendido el teólogo Erik Peterson. Éste pretendía realizar una crítica teológica de toda teología política. Consideraba la teología política como el producto de una interpretación helenística de la fe judía en Dios y como una doctrina totalmente ajena al cristianismo. Esta interpretación la hubiese podido suscribir Tertuliano, que judaizó la monarquía divina, y luego fue plenamente ejecutada por Eusebio de Cesarea, que vinculó la fe cristiana al imperium romanum en su panegírico de Constantino ${ }^{6}$. Pero en ese caso se trataba, para Peterson, de una teología política contraria a la fe cristiana, porque la doctrina de la Trinidad impide la posibilidad de concebir una realización política de la monarquía divina ${ }^{7}$ : «El imperium romanum, es la paz, la victoria del orden sobre la revuelta y sobre las facciones de la guerra civil: Un Dios - Un Mundo - Un Imperio». Para Peterson, este tipo de monarquía divina se corresponde exactamente con una teología política cristiana - ese Dios, que también fue Cristo, el Dios-Hombre de la Trinidad cristiana, es de un teológico-escatológico inadmisible-. Ya que sólo el retorno de Cristo al final de los tiempos traerá «la paz verdadera y la unidad verdadera del mundo» ${ }^{8}$. Esta separación de lo teológico y lo político en el dogma cristiano de la Trinidad ${ }^{9}$, así como la idea de una instau-

${ }^{4}$ Carl Schmitt, Politische Theologie II, 1969, reedición Berlín, Duncker und Humblot, 1984.

5 Ibidem, pp. 167-168.

${ }^{6}$ Eusèbe de Césarée, La théologie politique de l'Empire chrétien. Louanges de Constantin, París, Cerf, 2001.

7 Carl Schmitt, Politische Theologie II, op. cit.

8 Ibidem, p. 143.

9 Ibídem, p. 154: «Al final de su estudio, Peterson reitera su afirmación: la proclamación cristiana del Dios uno y trino está más allá del judaísmo y del paganismo, porque el misterio de 
ración de la paz como don de Dios, Schmitt las considera ficciones sobre las que reposa la leyenda de una liquidación teológica definitiva de la teología política. Con gran ingeniosidad, Schmitt pretende subrayar el fracaso del intento de Peterson y, por tanto, liquidar esta liquidación, demostrando que lo político en su sentido más fuerte habita en la propia Trinidad:

«Peterson hace una referencia decisiva, para la doctrina de la Trinidad cristiana, al citar un pasaje de Gregorio Nacianceno que contiene en su núcleo la siguiente formulación: El Uno - to hen- está siempre en rebeldía - stasiazon - contra él mismo — pros heauton. En el corazón de la formulación más irreprochable del espinoso dogma, aparece la palabra stasis, con el sentido de rebeldía [...]. La primera acepción de stasis es reposo, estado de reposo, posición, parada (status); es la noción contraria de kinesis: movimiento. Pero la segunda acepción de stasis es disturbio (político), movimiento, revuelta y guerra civil. [...] Incluso la simple yuxtaposición de numerosos ejemplos de tal oposición [entre esos dos significados] nos proporciona una mina para el conocimiento de los fenómenos políticos y teológico-políticos. En este caso, es una auténtica stasiología teológico-política la que aparece en el corazón de la doctrina trinitaria. Por tanto no se puede ocultar el problema de la enemistad y del enemigo ${ }^{10}$ ».

Es evidente la habilidad de Schmitt para derribar la posición de Peterson: es en el dogma mismo de la Trinidad, al que se supone puro de cualquier connotación política y que singularizaría la teología cristiana como virgen de toda implicación teológico-política, donde se encuentra el concepto político central, el del enemigo y el del conflicto. Por eso la liquidación definitiva de la teología política en Peterson no es más que una leyenda. La crítica schmittiana de Blumenberg sigue, por supuesto, otros derroteros. Consiste en mostrar que en la reivindicación radical de lo nuevo, en la afirmación de la libertad y de la autonomía humana enteramente desteologizadas, subsiste el remanente de una transposición teológico-política en las figuras de la agresividad y del enemigo en el sentido en que es el hombre mismo el que en adelante se vuelve contra el hombre: "Nero contra hominem nisi homo ipse» ${ }^{11}$. La liquidación científica de la teología política sería pues igualmente inútil ya que la misma tentativa de probar la legitimidad de los tiempos modernos contra la secularización y, en consecuencia, contra la teología política, paradójicamente sucumbe en el intento.

A partir de ahí surge una pregunta que no puede dejar de plantearse: ¿no está condenado al fracaso el proyecto de una crítica de toda teología política? ¿Un tercer intento de liquidar la teología política, tras Peterson y Blumen-

la Tri-unicidad sólo se realiza en la divinidad misma y no en la criatura, y también porque la paz que busca el cristiano, ningún emperador podría garantizarla: esa paz sólo puede ser un don de "Aquel que está más allá de toda razón"».

10 Ibídem, pp. 173-175.

11 Ibídem, p. 181, «Nadie está contra el hombre salvo el hombre mismo». 
berg, no va a saldarse con un impasse parecido? Me propongo demostrar aquí todo lo contrario situándome no en el plano teológico ni en el de la ciencia moderna, sino en el plano de la filosofía política, es decir, en el plano del propio Schmitt. Mi deseo es proponer la idea de una liquidación de la teología política schmittiana y no schmittiana como una tarea, una tarea que, tal como mostraré, ya ha sido emprendida pero de forma incompleta, así que debe ser retomada con nuevos bríos para llevarla a buen término. Si hablo de una tarea es porque creo que la filosofía política moderna (desde el siglo XVII hasta hoy), aunque se ha consagrado al proyecto de elaborar una explicación de lo político basado en fundamentos no teológicos (la razón, la historia, la costumbre, la fuerza, etc.), nunca se ha emancipado totalmente de la teología. Y eso es precisamente lo que se trata de lograr: llevar hasta el final la desteologización de lo político, emprendida pero no completada por la filosofía moderna. En este punto es absolutamente necesaria una precisión: la crítica de toda teología política no implica la idea de una desaparición de la religión. La religión es una cosa, la teología política otra muy distinta. La crítica de la teología política no es pues, en sí misma, un producto directo del ateísmo. No pretende demostrar que la religión no es más que una superstición. La crítica de toda teología política sólo supone una desacralización completa de lo político. Si es preciso liberarse de la teología política, es en razón de los peligros que encierra y que aquí podemos caracterizar con una fórmula: la presencia de lo sagrado en lo político. Acometer una crítica de toda teología política, una liquidación filosófico-política de la teología política, es querer expulsar lo sagrado de lo político, devolver lo político a su propia dimensión, es decir, a su relatividad, su historicidad y su precariedad.

La idea de una crítica de toda teología política no implica que no examinemos el campo completo de lo que podríamos llamar la historia política de Dios. Ésta se puede reconstruir mediante el estudio de las sucesivas figuras de Dios en la historia de la filosofía política o, de forma más amplia, en la historia del pensamiento político. Si fuese preciso elaborar esa historia, deberíamos hacer patente las representaciones políticas de Dios desde, digamos, la Antigüedad hasta nuestros días. Veríamos sucederse las figuras del Dios pastor, legislador, guerrero, gobernador, soberano, principio de orden que sólo actúa en nombre de la voluntad general, etc. Esta enumeración sólo es indicativa, en ninguna caso pretende ser exhaustiva. La historia política de Dios así concebida sería sin duda apasionante en el plano erudito, pero en el plano propiamente filosófico tendría escaso interés, o al menos tendría escaso interés para mí hoy. Elegiría un camino distinto: el de una evaluación de las figuras de lo teológico-político en la época moderna. Mi objetivo es, precisamente, demostrar que en la época moderna el esfuerzo para liberarse de la teología política nunca ha podido realizarse plenamente. Hay tres autores, muy distintos entre sí, que retendrán especialmente mi atención: Hobbes, Pascal y Rousseau. Ni que decir tiene que en estos tres autores no encontra- 
mos en modo alguno la misma teología política y, sin embargo, sí puede haber algo en común entre ellos y que ese algo defina el lugar de la teología política en la época moderna. Este lugar no puede interpretarse ni en términos schmittianos de secularización, ni en los términos de Blumenberg como pura autoafirmación del hombre y retroceso irrevocable de lo divino. Por decirlo en pocas palabras, tiendo a pensar que al abordar con nuevos bríos la cuestión del fundamento de la autoridad política y de la legitimidad, los pensadores modernos rompieron con una figura medieval de la teología política que descansaba sobre una jerarquía estable de lo espiritual y de lo temporal, de lo eclesiológico y de lo político. El orden político debía poder pensarse como algo fundado en el derecho, la fuerza o la costumbre, sin presuposición teológica. Sin embargo, para la filosofía moderna, esta posición no era defendible hasta sus últimas consecuencias y por eso la cuestión teológica reaparecía una y otra vez en el centro de la cuestión política. Este retorno se producía de distintas formas que trataré de examinar. No obstante, el retorno de lo teológico nunca se producía a la fuerza, sino que venía a doblar o a redoblar, por decirlo así, un intento de pensar la autonomía de lo político que resultaba insuficiente o incompleta. Intentaré, pues, demostrar cómo en el esfuerzo de romper con una teología política de la subordinación del poder temporal al espiritual, el pensamiento moderno se ha no ya liberado de toda teología, sino que ha reinventado nuevas modalidades de lo teológico-político.

Una vez demostrado lo anterior, la cuestión seguirá siendo saber si lo político está necesariamente condenado a un retorno de lo teológico, o dicho de otro modo, si lo teológico-político no es el horizonte infranqueable de la política. Aquí me adelanto a mi desarrollo y señalo desde ahora que mi respuesta será negativa. Es de todo punto importante, por el contrario, pensar lo político sin lo teológico y lo teológico sin lo político, y por tanto operar una crítica radical de lo teológico-político para devolverle a lo político su relatividad, su historicidad y su precariedad, que definen su estatuto ontológico propio. Sin embargo, semejante emancipación de lo político con respecto a lo teológico, y cuya correlación es una emancipación de lo teológico con respecto a lo político, no significa en absoluto una crítica o una reducción de la religión.

Pero antes de abordar los dos puntos que acabo de indicar, a saber, por una parte, el retorno de lo teológico en las concepciones políticas de la época moderna y, por otra, la exigencia de romper la estructura teológico-política en general, es decir, de restarle todo carácter sagrado a lo político y todo carácter político a lo sagrado, lo que equivale a situar de nuevo a lo político, como dije antes, en su relatividad, en su historicidad y en su precariedad, me gustaría subrayar el peligro de la concepción de lo teológico-político como resacralización de lo político en Carl Schmitt, lo que me permitirá explicar mejor por qué opino que una crítica de lo teológico-político es hoy indispensable. 


\section{Lo teológico-político como sacralización de lo político en Carl Schmitt}

Según Carl Schmitt, lo teológico-político es el horizonte decisivo e infranqueable de lo político. En otras palabras, la verdad de una posición, de una teoría o de una filosofía política se dilucida en el plano teológico. Toda política tiene, de alguna manera, una teología implícita. Así es como la idea de un Dios todopoderoso está ligada a la de la soberanía política o a la del legislador omnipotente, no sólo en el plano filosófico sino también en el plano de un análisis sociológico de los conceptos. La teología define una estructura del mundo que hace posible un tipo de pensamiento político: «La situación excepcional tiene para la jurisprudencia el mismo significado que el milagro para la teología» ${ }^{12}$. Es con la idea de la omnipotencia divina y de la soberanía como se estableció la estructura teológico-política característica del siglo XVII. Esto es válido para Descartes, Hobbes y otros muchos. En lo que respecta a Descartes, la definición que da de la posición de Dios en el sistema del mundo se corresponde con la posición del monarca en el Estado. Schmitt recuerda la afirmación de Descartes en una carta a Mersenne, el 15 de abril de 1630: «Es Dios quien ha establecido sus leyes en la naturaleza, al igual que un rey establece unas leyes en su reino». Sobre una estructura del mismo tipo está fundada la teoría de la soberanía en Hobbes, que defiende la idea de una decisión última:

«A la noción de Dios en los siglos XVII y XVIII pertenece la trascendencia de Dios ante el mundo, al igual que la trascendencia del soberano ante el Estado pertenece a la filosofía del Estado» ${ }^{13}$.

Omnipotencia divina/soberanía política, milagro/excepción, voluntad libre de Dios/decisión soberana que emerge ex nihilo sin razón ni deliberación, éstas son algunas de las parejas de conceptos que definían una estructura teológico-política en el marco de la que se despliega el concepto de la autonomía política con respecto a todas las demás esferas de la vida social y económica. En oposición a esta teología política, hay otra que la niega y en el marco de la cual el liberalismo y el Estado de derecho pueden concebirse:

«Pues la idea del Estado de derecho moderno se impone con el deísmo, con una teología y una metafísica que rechazan el milagro sobrenatural y rechazan la ruptura de las leyes naturales, ruptura contenida en la noción de milagro que implica una excepción debida a una intervención directa, al igual que rechazan la intervención directa del soberano en el orden jurídico existente. El racionalismo de la Aufklärung condenó toda forma de excepción» ${ }^{14}$.

12 Politische Theologie I, p. 46.

13 Ibídem, p. 58.

14 Ibidem, p. 46. 
La idea del Estado de derecho, que según Schmitt está ligada al positivismo jurídico, al normativismo, pero también al parlamentarismo y al liberalismo, presenta una visión debilitada del Estado en adelante despolitizado: «Ya que en la base de su identificación, respecto al Estado de derecho, entre Estado y orden jurídico, hay una metafísica que identifica legalidad de la naturaleza y legalidad normativa. Surge de un pensamiento marcado exclusivamente por las ciencias naturales, se basa en el rechazo de todo lo "arbitrario" y pretende expulsar cualquier excepción del dominio del espíritu humano» ${ }^{15}$. El Estado de derecho es, así, el aspecto jurídico de una institución pública reducida a una maquinaria económica, administrativa y policiaca donde la decisión política queda reducida a casi nada, es decir, una institución despersonalizada y desustancializada.

En otra parte he mostrado cómo las posiciones teológico-políticas de Schmitt no podían en ningún caso tener sus fuentes y su justificación en autores a los que se remite, en especial Jean Bodin y Thomas Hobbes. Ni el concepto de decisión ex nihilo (sin deliberación ni razón), ni el de excepción están implicados en el concepto moderno de soberanía tal como aquéllos lo formularon. Lejos de que la soberanía esté ligada a una teoría de la situación excepcional suspensiva del orden jurídico, permite por el contrario a Bodin y a Hobbes reducir la excepción a un caso particular de la norma, es decir, a incluirla en el orden jurídico. De la misma forma, la crítica schmittiana del Estado de derecho y del liberalismo descansa sobre el postulado de que no hay liberalismo político, sólo liberalismo económico o administrativo. Lo que es evidentemente falso: el liberalismo francés del siglo XIX con B. Constant y A. de Tocqueville en particular, permite establecer fácilmente lo contrario. Volveré sobre el tema al final de este estudio.

Analizada en el plano de su fundamento teológico, la oposición entre el Estado soberano y el Estado liberal de derecho no es la oposición entre dos teorías de la institución política o dos opciones prácticas entre las que es preciso elegir, sino el enfrentamiento de dos dogmas marcados uno por la determinación de verdad y el otro por la de falsedad. No se trata de una antinomia entre dos puntos de vista, relativizados e historizados, sino de la incompatibilidad de dos actos de fe contrarios y exclusivos entre sí. Lo teológico-político equivale aquí a una resacralización de lo político. Todo ocurre, pues, como si en este plano la oposición de razones políticas se transformase en una oposición de dogmas teológicos entre los que no puede haber un compromiso sino sólo una exclusión recíproca. Las páginas que Schmitt le dedicó a «La filosofía del Estado en la contrarrevolución (de De Maistre, Bonald, Donoso Cortés)» ${ }^{16}$ extraen con el concepto de dictadura, las consecuencias últimas de la teologización de lo político: «Donoso estaba convencido de que había llegado la hora del último combate; ante el mal radical, sólo queda la dictadura» ${ }^{17}$.

\footnotetext{
15 Ibidem, p. 50.

16 Ibídem, pp. 62-75.

17 Ibidem, p. 74.
} 
Último combate, mal radical, decisión pura, dictadura, son los conceptos alrededor de los cuales se establece un pensamiento que teologiza lo político. Éste es, hoy día, el mayor peligro porque borra la especificidad de las categorías políticas. Es portador de una visión apocalíptica de lo político ligado a una sacralización del poder, a la lucha a muerte contra el enemigo (interior o exterior), a la supresión de todos los límites que le fijan a la guerra las nociones de interés o de poder. Lo político ya no es el terreno de lo relativo sino de lo absoluto, el terreno donde está en juego la causa de Dios, de la verdad, de la civilización, de la salvación, etc. En vez de ser el lugar de los conflictos de derechos, de intereses o de poderes, lo político se convierte en el lugar del bien absoluto y del mal radical, de lo puro y de lo impuro, de Cristo y del anticristo.

\section{El retorno por partida doble de lo teológico-político en los tiempos modernos}

Los impasses de la versión schmittiana de lo teológico-político están muy alejados de la realidad efectiva de la reflexión teológico-política de los filósofos modernos. Schmitt pretende ser el heredero de esos filósofos (Bodin y Hobbes en especial) —o al menos de algunos de ellos-, aunque lo cierto es que los traiciona. Lejos de ser la totalización o la culminación del pensamiento político moderno ${ }^{18}$, es su negación. En efecto, lo que caracteriza en primer lugar a la época moderna es más bien una tentativa de pensar lo político como algo ajeno al marco teológico-político habitual. Subrayo la palabra tentativa porque su propósito nunca llegará a convertirse en una crítica radical de lo teológico-político. En otras palabras, si la filosofía moderna se caracteriza por la exigencia de autonomizar la política respecto de la teología, si le debe su especificidad a la implementación de ese enfoque, no supo o no pudo llevar su proyecto hasta el final. De ahí que lo teológico intervendrá en lo político retornando y superando una definición al principio puramente racional de lo político, o en clave de suplemento encargado, en principio, de consolidar el edificio ya construido, pero que en realidad modifica profundamente su significado. Intentaré demostrarlo en tres autores muy distintos entre sí: Hobbes, Pascal y Rousseau.

\section{A. Hobbes: de la subordinación de la Iglesia a la resacralización del Estado}

La cuestión teológica interviene en la obra de Hobbes en tres niveles. En el Leviatán, aparece en el capítulo XII, dedicado por entero a la religión. Ésta es estudiada como una pasión compleja, por tanto, como una pasión relacional:

18 En términos generales, es la tesis de Carlo Galli en su libro Genealogia della politica, Carl Schmitt e la crisi del pensiero politico moderno, Bolonia, Il Mulino, 1996. 
la más importante de todas si consideramos las consecuencias políticas de las pasiones. La formación de la religión es concebida a partir de sus gérmenes naturales en la naturaleza humana. Así, la idea de Dios se deriva bien de la ignorancia de las causas naturales que incita a creer en un poder invisible que domina la naturaleza, bien, al contrario, del conocimiento completo de esas causas que conduce a la idea de un «Dios eterno, infinito y todopoderoso» creador de la naturaleza.

El problema de Dios aparece de nuevo con la pregunta sobre el fundamento de la obligación, más concretamente, sobre el fundamento moral de la obligación, que es diferente del fundamento político de la obligación, pero que éste presupone.

Pero la cuestión teológico-política como tal es planteada a propósito de la teoría de la obediencia, bajo la forma de una contradicción capital que puede poner en peligro el edificio político: la que puede establecerse entre la obediencia al soberano y la obediencia a Dios.

«El pretexto más frecuente de los desórdenes y de la guerra civil en las repúblicas cristianas radica, desde hace tiempo, en una dificultad que, a día de hoy, no ha sido resuelta satisfactoriamente: la que consiste en obedecer a la vez a Dios y al hombre cuando sus mandamientos son contrarios [...]. Pero esta dificultad de obedecer a la vez a Dios y al que en la tierra es el soberano civil no puede detener a los que saben distinguir entre lo que les resulta necesario y lo que no les resulta necesario para ser recibidos en el reino de Dios» ${ }^{19}$.

Según Hobbes, lo que resulta necesario para la salvación está contenido en dos principios: 1) la obediencia a las leyes del Estado y 2) la creencia en este único artículo de fe: Jesús es Cristo. Ahora bien, el fundamento de la obediencia y su distinción de la fe se encuentran en el concepto de soberanía. Es, en efecto, la redefinición del concepto de soberanía lo que impide cualquier veleidad de invasión del poder eclesiástico en el poder político. Hobbes utiliza así la definición de soberanía como instancia de decisión política absoluta e indivisible, dotada de derecho y poder, capaz de mandar y de obligar, para refutar las tesis del cardenal Belarmino en su De Summo Pontifice. Esta definición de la soberanía como una, absoluta e indivisible permite, en efecto, rechazar de entrada toda tesis que implique directa o indirectamente que tengamos que servir a dos amos. Esto es lo que escribe Hobbes contra Belarmino:

«El sexto pasaje, tomado de Romano XXIII, dice así: que toda alma se someta a los poderes superiores, pues no hay más poder que Dios, lo que debe ser obedecido dice [Belarmino] no sólo por los príncipes seculares sino también por los príncipes eclesiásticos. A lo que yo respondo, primero, que

19 Hobbes, Leviathan, edición MacPherson, Penguin Classics, Harmondsworth, capítulo XLIII, pp. 609-610. 
no hay más príncipes eclesiásticos que los que son también soberanos civiles, y que su principado no excede el dominio de su soberanía civil: fuera de estos límites, aunque pueden ser recibidos como doctores, no pueden ser reconocidos como príncipes. En efecto, si el Apóstol hubiese querido decir que debíamos someternos a la vez a nuestros propios príncipes y al Papa, nos hubiese enseñado algo que Cristo en persona dijo que era imposible, a saber, servir a dos amos» 20 .

Es, pues, la definición unívoca de la soberanía lo que ahora permite dar una definición unívoca de los conceptos de poder, de mandamiento, de obediencia y operar a la vez una distinción radical entre las funciones políticas y las funciones eclesiásticas y la unificación de las dos en la persona del soberano civil. Así, con una mano Hobbes pretende asegurar la autonomía de lo político (la relación mando-obediencia) con respecto a toda pretensión hegemónica del poder espiritual o religioso, pero con la otra, busca igualmente impedir que el poder espiritual se emancipe, se autonomice por su lado y, en definitiva, se oponga desde fuera al poder político. Por eso Hobbes distingue radicalmente las funciones política y eclesiástica pero, al mismo tiempo, las unifica haciendo que las asuma la instancia política suprema: el soberano civil. Sin duda se puede decir que esta unificación terminal se traduce en una disolución de lo religioso en lo político, pero esta disolución no es neutra sino que, por el contrario, le confiere un barniz religioso a todo el edificio político. En cierta forma, Hobbes se ve arrastrado no sólo más lejos, sino incluso en sentido contrario de lo que pretendía establecer. De inicio, Hobbes pretendía establecer la autonomía de lo político y su hegemonía sobre lo religioso. Pero finalmente produce un retorno de lo religioso en lo político: una coloración religiosa de lo político. Así se comprende por qué es posible hablar de un retorno de lo teológico que, a la vez y contradictoriamente, culmina y cuestiona la autonomía de lo político que se pretendía al principio. El retorno de lo teológico, en efecto, no podía dejar la institución política intacta. Para medir sus consecuencias, basta recordar que implica la doble identificación entre 1) el soberano político y el pastor supremo en la persona civil del soberano; 2) entre el Estado y la Iglesia en la idea de una república cristiana.

Todas las determinaciones teológicas del soberano político: es el lugarteniente de Dios, ejerce sus funciones de pastor supremo «en virtud de una autoridad recibida directamente de Dios, es decir, por derecho divino, iure divino» ${ }^{21}$, mientras que los obispos sólo ejercen su cargo en virtud de la autoridad del soberano civil, es decir, iure civili; el conjunto de estas determinaciones teológicas intervienen en principio para neutralizar el poder eclesiástico, pero de hecho lo reinscriben en el corazón de lo político. En consecuencia, lo teológico-político es en Hobbes el redoblamiento teológico de una teoría del Estado que ha sido elaborada con anterioridad e inde-

20 Ibídem, XLII, p. 589.

21 Ibidem, XLII, p. 570. 
pendientemente de toda teología, pero que se encuentra desde ese momento comprometida en su aspiración esencial de afirmar la autonomía de lo político.

\section{B. Pascal: de la desteologización radical de lo político a su justificación figurativa}

Pascal se replantea igualmente el fundamento de la autoridad política desde una perspectiva que desecha de entrada cualquier cuestión teológico-política. Esta afirmación puede parecer paradójica en razón de la radicalización en él de la teología de la caída: exilio del mundo lejos de Dios, segunda naturaleza corrompida del hombre, errancia de su deseo, inaccesibilidad de la justicia, impotencia de la razón, etc. Es verdad que las concepciones políticas de Pascal en el legajo «Razones de los efectos» de los Pensamientos o en los Tres discursos sobre la condición de los grandes presuponen la recuperación del dogma agustiniano del pecado original y de la corrupción. Pero estas posturas teológicas están precisamente en el fundamento de una separación entre lo teológico y lo político. Al igual que la ausencia de Dios abre la naturaleza a un conocimiento exclusivamente científico que sólo depende de la experiencia y de la razón y en absoluto de la Escritura, de la tradición o de la fe según los términos del prefacio de Tratado del vacio, asimismo el alejamiento del deseo y de la voluntad humana de Dios es la condición para una autonomización del mundo humano y en concreto del orden político. Sin duda, la autonomía poslapsaria del hombre y de la política está evidentemente afectada por un coeficiente negativo, por oposición a la heteronomia de la voluntad humana, es decir, su dependencia prelapsaria de la voluntad de Dios que está afectada por un coeficiente positivo, lo que no implica que esa autonomía no sea verdadera. Pascal es sin duda el que llevó más lejos la idea de una autonomía de lo político. Es esa autonomía la que puede explicar el realismo mediante el cual se inscribe en la tradición de Maquiavelo, así como su pesimismo radical sobre la posibilidad de reunir la justicia y la fuerza en este mundo, e incluso su cinismo respecto a la ciudad de los hombres, que compara con un asilo de locos. La política de Pascal está fundada en un desmembramiento de lo teológico y lo político que emancipa lo político liberándolo de toda perspectiva teológico-política. Así se comprende cómo las concepciones políticas de Pascal pueden retomar en muchos puntos las posiciones de un pensador tan anticristiano como Maquiavelo. De modo que la autoridad política está fundada únicamente sobre la fuerza, el azar, la costumbre, la opinión y la imaginación. Estas nociones definen el orden político, no encierran en sí mismas ningún componente teológico, por el contrario, desteologizan totalmente lo político y también lo desmitifican: la razón, la justicia, el contrato no son en verdad más que ilusiones o engaños. 
En el principio de lo político está, según los Pensamientos, el golpe de fuerza ${ }^{22}$. Este establece una relación de fuerza entre vencedores y vencidos y, en consecuencia, un partido dominante: cuerdas de necesidad. La institución política propiamente dicha nace con la transformación de las cuerdas de necesidad en cuerdas de imaginación que institucionalizan la relación de fuerza. La fuerza no puede perpetuarse a sí misma, por tanto hay que poner fin a la guerra real o virtual. Es ahí donde la imaginación debe entrar en escena y asegurar la institucionalización de la fuerza, es decir, en concreto, la naturaleza de la sucesión en el poder mediante el reino de la apariencia. La costumbre y la opinión se encargarán del resto para establecer en los espíritus y en las costumbres las leyes, las distinciones, las órdenes, etc. El principio de lo político permanece subyacente en sus metamorfosis. La verdad de lo político es la fuerza, pero la fuerza oculta, enmascarada, transfigurada en su otro: la justicia. La justicia en sí no pertenece a lo político, por eso «al no poder hacer que sea obligatorio obedecer a la justicia, se ha hecho de modo que sea justo obedecer a la fuerza. Al no poder fortalecer a la justicia, se ha justificado la fuer$\mathrm{za}$, a fin de que el justo y el fuerte vayan juntos y que la paz sea el bien soberano» ${ }^{23}$.

En los Tres discursos sobre la condición de los grandes, el principio es distinto: en el principio de lo político está el azar y la ilusión. Todo rey es rey por azar y por equivocación ${ }^{24}$. Señalemos ante todo que los Tres discursos comportan el cuestionamiento más radical de los modos tradicionales de legitimación de la autoridad política. Ni la naturaleza, ni la virtud, ni la historia pueden asegurar un fundamento estable a la legitimidad del poder ${ }^{25}$. Lo que consideramos legítimo reposa en realidad sobre la ilusión del pueblo ${ }^{26}$. Éste es el significado de los Tres discursos. Nunca se había llegado tan lejos en la desacralización de lo político. Los Pensamientos también incluyen la misma

22 Cf. Pascal, Pensées, edición Lafuma de las Obras completas, París, Seuil, 1963, fragmento 828 .

23 Ibídem, fragmento 81.

24 «Un hombre es arrojado por la tempestad a una isla desconocida cuyos habitantes no lograban encontrar a su rey, que se había perdido; el hombre, al tener un gran parecido de cuerpo y de rostro con el rey, es confundido con él y reconocido como tal rey por todo el pueblo. Al principio el hombre no sabía qué hacer, pero finalmente decidió aceptar su buena fortuna. Recibió todos los respetos que le rindieron y se dejó tratar como un rey», Trois Discours sur la condition des grands, edición Lafuma de las Obras completas, op. cit., p. 366 A.

25 «No imaginéis que el azar por el que poseéis las riquezas que atesoráis es menor que el que convirtió a ese hombre en rey. No tenéis más derecho a ellas por vos mismo ni por vuestra naturaleza que él a ser rey. Y si sois hijo de un duque, más aún, si os encontráis en el mundo, es sólo por una infinidad de azares», ibídem.

26 «El pueblo que os admira tal vez no conoce este secreto. Cree que la nobleza es una grandeza real y casi considera que los grandes son de naturaleza distinta a los demás. Si queréis, no los saquéis de ese error; pero no abuséis de esa elevación con insolencia, y sobre todo no os equivoquéis vos mismo creyendo que vuestra persona tiene algo que la hace más elevada que la de los demás», ibídem, pp. 366 B-367 A. 
idea: «El poder de los reyes está fundado sobre la razón y sobre la locura del pueblo, y mucho más en la locura. La cosa más grande e importante del mundo tiene su fundamento en la debilidad. Y esos cimientos son admirablemente seguros, pues no hay nada más seguro que eso, que el pueblo será débil. Lo que está basado en la sana razón está muy mal fundado, como la estima de la sabiduría» ${ }^{27}$.

Autonomía de lo político, desmoronamiento de los cimientos tradicionales de la legitimidad y desacralización radical del poder van juntos y funcionan admirablemente en la exigencia de un desdoblamiento del pensamiento —uno público, el otro oculto- de los grandes. «Si el pensamiento público os eleva por encima del hombre común, que el otro os rebaje y os mantenga en perfecta igualdad con todos los hombres, pues ése es vuestro estado naturral» ${ }^{28}$. El rey está desnudo, el poder desenmascarado y el funcionamiento político descifrado. Ya vemos hasta dónde nos arrastra la desacralización de la autoridad política ${ }^{29}$.

Pero lo que el agustinianismo abandonó con una mano, permitiendo concebir la autonomía de lo político, lo recupera con la otra. Si al principio había separación de lo teológico y de lo político, al final hay un retorno de lo teológico-político bajo una forma reforzada. Y es que detrás de la autonomía se esconde la figura: si hay un rey humano es sólo por azar y sustitución porque el verdadero rey es otro muy distinto, es el Dios oculto. Detrás del orden político manifiesto, que es el de la concupiscencia, está el orden oculto de la caridad: «Se han fundado y extraído de la concupiscencia unas reglas admirables de orden, de moral y de justicia. Pero en el fondo, en ese fondo malvado del hombre, ese figmentum malum sólo está oculto. No ha sido arrancado» ${ }^{30}$, a esto hay que añadir «Grandeza del hombre, incluso en su concupiscencia, por haber sabido extraer de ella un arreglo admirable y haberla convertido en un cuadro de caridad» ${ }^{31}$. El retorno de una teología política de tipo agustiniano impregna toda la teoría política. Es como si lo político, al quedar desnudo por el movimiento de desacralización, hubiese inspirado un pavor terrible que había que compensar con una resacralización reforzada hasta en la definición de la legitimidad de la autoridad de los títulos y de los bienes: «No pretendo decir que no os pertenecen legítimamente [vuestros bienes], ni que le esté permitido a cualquiera arrebatároslos, pues Dios, que es el dueño de todos los bienes, le ha permitido a las sociedades hacer leyes para compartirlos; y una vez establecidas dichas leyes, es injusto violarlas» ${ }^{32}$.

27 Pensées, op. cit., fragmento 26.

28 Trois Discours, op. cit., p. 366 B.

29 Cf. Yves Charles Zarka, Hobbes et la pensée politique moderne, París, PUF, 1995, $2 .{ }^{\text {a }}$ edición 2001, capítulo XII «Hobbes et Pascal: deux modèles de théorie du pouvoir».

30 Pensées, fragmento 211.

31 Ibídem, fragmento 118.

32 Trois Discours, op. cit., p. 366 B. 
Es la restitución de lo político en el desgarro de los órdenes inconmensurables lo que hace reaparecer la dimensión teológico-política.

\section{Rousseau: de la soberanía del pueblo a la religión civil}

Rousseau abre la reflexión a un interrogante fundamental sobre el derecho en política al situar en el centro de su teoría política la cuestión de la legitimidad del poder y al demostrar que ésta no puede ser resuelta por la vía de Dios, de la naturaleza o de la historia. Es en el marco de este interrogante donde la soberanía queda directamente ligada a la legitimidad, lo que no ocurría anteriormente. En adelante, no basta con definir las condiciones de una república soberana, eso ya lo hacían a la perfección Bodin y Hobbes, sino que es preciso, además, que esa soberanía no sea usurpada, que sea pues legítima y que se definan las condiciones de esa legitimidad. No hace falta decir que esta aparición de la cuestión de la legitimidad en el primer plano de la teoría política sólo es posible dejando a un lado toda referencia a una teología política del derecho divino o al origen divino del poder, cuyo efecto sería, por el contrario, prohibir que la cuestión se plantease realmente, como acabamos de ver en Pascal. La antropología política de Rousseau supone el rechazo de toda perspectiva teológico-política, ésa es incluso la condición clave para que su principal innovación en materia de filosofía política pueda sobrevenir: hacer del pueblo de facto (y no sólo en potencia o virtualmente) el único sujeto político legítimo, el único sujeto legítimo de la soberanía ${ }^{33}$. La cuestión central radica en el acto por el que un pueblo es un pueblo, es decir, la primera convención: el contrato social originario que funda simultáneamente el pueblo, la soberanía y el Estado.

Sin embargo, aunque plantea la cuestión del derecho - ¿qué derecho tiene el poder? - o de los títulos de legitimidad del poder en términos exclusivamente antropológico-políticos y, por tanto, ajenos a toda teología natural o revelada que nada tienen que decir al respecto ${ }^{34}$, Rousseau parece incapaz de seguir en esta dirección hasta el final y él también opera de un modo específico un retorno de lo teológico-político que tendrá lugar en su definición de la soberanía. Hay en Rousseau, en efecto, una absolutización de la soberanía más fuerte que en sus predecesores. El soberano de Hobbes, por ejemplo, es mucho menos absoluto que la voluntad general de Rousseau porque no puede eliminar el derecho de resistir al poder político que le pertenece al ser mismo del individuo. «Se le obligará a ser libre» es una afirmación del todo inconce-

33 Cf. Yves Charles Zarka, «Le tournant rousseauiste ou la réinvention de la souveraineté du peuple», en Gian Mario Cazzaniga e Yves Charles Zarka, Penser la souveraineté à l'époque moderne et contemporaine, 2 vols., Pisa/París, ETS/librairie Vrin, 2001, vol. 1, pp. 287-302.

34 «Toda potencia viene de Dios, lo reconozco, pero toda enfermedad también viene de Él. ¿Significa eso que está prohibido llamar al médico?», Du contrat social, I, 3, Obras completas, París, Gallimard, col. La Pléiade, vol. III, p. 355. 
bible en Hobbes. Ahora bien, la absolutización rousseauniana es al mismo tiempo una sacralización. Aquí dejamos atrás el lenguaje de la antropología política y de la moral para alcanzar el de la teología: «El soberano, por el solo hecho de ser, dice Rousseau, es siempre lo que debe ser» ${ }^{35}$. El ser que es siempre lo que debe ser es, tradicionalmente, el ser divino. Así, la voluntad general es indestructible y por tanto no puede ser ni aniquilada ni corrompida: «es siempre constante, inalterable y pura», aunque sí puede ser hurtada ${ }^{36}$. La soberanía, definida por la fuerza legislativa cuyo sujeto sólo puede ser el cuerpo entero del pueblo, es inalienable, indivisible, siempre recta - aunque puede errar-, tiene siempre por objetivo el interés común, y sagrado: «... el poder soberano es del todo absoluto, del todo sagrado, del todo inviolable...».

Esta sacralización de la soberanía tal vez no aparece nunca con tanta fuerza como en el capítulo del Contrato social «Del derecho de vida y de muerte». Para subrayar su alcance, conviene recordar que en Hobbes, por ejemplo, este derecho resulta profundamente problemático: no puede estar fundado en la convención social y aparece, pues, como el retorno de un arcaísmo en el seno mismo del Estado ${ }^{37}$. Por su parte, Montesquieu tiende a considerar el derecho de gracia, y no el derecho de vida y de muerte, como un atributo de la soberanía. Pero en Rousseau, por el contrario, no hay derecho más cierto de la soberanía que el derecho de vida y de muerte:

«Quien desea conservar su vida a expensas de los demás debe también entregarla por ellos cuando sea preciso. Pero el ciudadano no es juez del peligro al que la ley quiere que se exponga, y cuando el príncipe le dice: al Estado le conviene que mueras, debe morir, ya que sólo bajo esa condición ha vivido en seguridad hasta entonces, y porque su vida no es sólo un favor de la naturaleza, sino un don condicional del Estado» ${ }^{38}$.

La sacralización de la soberanía explica por qué toda infracción al derecho social es considerada como una rebelión o una traición que excluye al que la comete de su pertenencia al cuerpo social. El criminal o el malhechor, sea quien fuere, rompe con su acto el tratado social: es desposeído de su condición de persona moral y puede ser exiliado o condenado a muerte como enemigo público. Así, la sacralidad de la soberanía del pueblo es concebida exactamente a partir del modelo de sacralidad de la persona del rey, contra la que sin embargo se afirmó asumiendo sus atributos. El exilio o la muerte debe castigar a la persona impura, por así decirlo, que ha atentado contra lo sagrado y que no puede volver a ser miembro del Estado. Es cierto, y el propio Rousseau lo subraya, que el soberano no puede pronunciar una condena particular, pero ésta se ejecuta en su nombre: «Pero, me dirán, la condena de

\footnotetext{
35 Ibídem, I, 7, p. 363.

36 Ibidem, IV, 1, p. 438.

${ }^{37}$ Cf. Yves Charles Zarka, Hobbes et la pensée politique moderne, op. cit., pp. 228-250.

38 Contrat social, II, 5, p. 376.
} 
un criminal es un acto particular. De acuerdo, y por eso tal condena no le pertenece en absoluto al soberano; es un derecho que puede conferir sin poder ejercerlo él mismo» ${ }^{39}$. De esto se deriva, evidentemente, que en adelante el derecho de gracia se convierte en algo bastante incierto:

«Respecto del derecho de gracia, o de eximir a un culpable de la pena fijada por la ley y pronunciada por el juez, sólo le corresponde al que está por encima del juez y de la ley, es decir, al soberano. Pero su derecho al respecto no está muy claro, y los casos en que puede ejercerlo son muy raros» ${ }^{40}$.

Por si necesitábamos una confirmación suplementaria de esta sacralización de lo secular, la encontramos en el penúltimo capítulo del Contrato social, «De la religión civil». Rousseau se propone demostrar que antes del cristianismo no había separación entre lo teológico y lo político, ni siquiera en el caso de los hebreos: «Dado que cada religión estaba unida a las leyes del Estado que la preceptuaba, el único modo de convertir a un pueblo era sometiéndolo. No había más misioneros que los conquistadores y como la obligación de cambiar de culto era de ley para los vencidos, había que empezar por vencer antes de hablar de religión» ${ }^{41}$. Es, pues, con el cristianismo cuando lo teológico y lo político se separan, provocando «las divisiones intestinas que nunca han dejado de agitar a los pueblos cristianos» ${ }^{42}$. Rousseau extrae dos

39 Ibídem, p. 377.

40 Ibídem.

41 Ibidem, IV, 8, p. 461.

42 Ibídem, p. 462. La denuncia de Rousseau sobre los efectos políticamente nocivos del cristianismo parece inspirada por los Discorsi de Maquiavelo. Rousseau se expresa en estos términos: «Pero me equivoco al hablar de una República Cristiana, ya que cada una de estas dos palabras excluye a la otra. El Cristianismo sólo predica servidumbre y dependencia. Su espíritu es tan favorable a la tiranía que ésta siempre aprovecha la oportunidad. Los verdaderos cristianos están hechos para ser esclavos; ellos lo saben y no por eso se alarman lo más mínimo; esta vida tan breve tiene muy poco valor a sus ojos» (ibidem, p. 467). Podemos comparar las palabras de Rousseau con este pasaje de Maquiavelo: «Al preguntarme, pues, sobre la causa por la que en los tiempos antiguos los pueblos estaban más apegados a la libertad que hoy, creo que esto proviene de la misma causa que hace que los hombres de hoy sean menos valientes. Creo que es la diferencia que existe entre nuestra educación y la de nuestros antepasados, que proviene de la diferencia entre nuestra religión y la antigua. Al enseñarnos la verdad y el camino justo, nuestra religión ha hecho que tengamos en menor estima el honor mundano. Los paganos, al considerar el honor como el bien supremo, se mostraban más encarnizados en sus acciones. Podemos observarlo en muchas de sus instituciones, empezando por la magnificencia de sus sacrificios en comparación con la humildad de los nuestros, cuya pompa es más delicada y magnífica, pero donde nada resulta feroz ni violento. Entre los paganos no faltaba ni la pompa ni la magnificencia en las ceremonias, pero se venía a sumar el sacrificio, sangriento y horrible, puesto que se mataba gran cantidad de animales. Tan terrible espectáculo volvía a los hombres iguales a él. Además, la religión antigua sólo recompensaba a los hombres cubiertos de gloria terrenal, como los generales y los jefes de Estado. Nuestra religión glorifica más a los hombres humildes y contemplativos que a los hombres de acción. Además, nuestra religión escogió como bien supremo la humildad, la sumisión y el desprecio de las cosas humanas. La antigua religión eligió la grandeza del alma, la fuerza del cuerpo y todas las demás cosas aptas 
conclusiones. La primera consiste en afirmar que, después de todo, fue Hobbes quien mejor identificó tanto el mal como el remedio al proponer reunir lo teológico y lo político bajo la égida de este último. Este punto merece subrayarse ya que es uno de los pocos en que Hobbes no sólo no es condenado, sino que es aprobado: «Entre todos los autores cristianos, el filósofo Hobbes es el único que ha visto claramente el mal y el remedio, el único que se atrevió a proponer la unión de las dos cabezas del águila y así reducirlo todo a la unidad política, sin la cual ningún Estado ni gobierno estará nunca bien constituido» ${ }^{43}$. El segundo punto consiste, para Rousseau, en definir una religión civil que tenga por objeto llevar a todos los ciudadanos a «amar sus deberes», religión en la que el soberano político fija «los artículos, no precisamente como dogmas de religión, sino como sentimientos de sociabilidad, sin los que es imposible ser un buen ciudadano ni un súbdito fiel» ${ }^{44}$. Ahora bien, cuando examinamos el tenor de la religión civil, nos damos cuenta de que algunos de sus artículos de fe son propiamente teológicos (la existencia de la divinidad, la vida futura, la felicidad de los justos y el castigo de los malvados) y otros teológico-políticos: la santidad del contrato. En último término, así se ve realizada la sacralización de lo secular que hemos ido encontrando en los distintos momentos constitutivos de la doctrina de la soberanía del pueblo. En adelante, no sólo el contrato social sino también la legislación del Estado se ve sacralizada en «una especie de catecismo del ciudadano» ${ }^{45}$.

En consecuencia, lo teológico-político interviene en el pensamiento político moderno no tanto como una estructura de partida o un elemento original, sino como un redoblamiento de un fundamento político pensado primero como algo autónomo. En adelante, las preguntas fundamentales son las siguientes: ¿es inevitable el retorno de lo teológico? ¿Lo teológico-político es el horizonte infranqueable de lo político? Ahora intentaré demostrar que estas preguntas deben contestarse con una negativa.

para hacer fuertes a los hombres. Aunque nuestra religión exige que seamos fuertes, quiere que seamos más aptos para el sufrimiento que para cosas fuertes. Esta forma de vivir, por tanto, parece haber debilitado al mundo y ha hecho que sea presa de los malvados. Éstos pueden dominarlo eficazmente ya que observan que, para ir al paraíso, el conjunto de los hombres piensa más en soportar los golpes que en vengarse. Aunque parece que el mundo se ha afeminado y el Cielo desarmado, esto sin duda proviene de la cobardía de los que han interpretado nuestra religión en términos de ociosidad y no en términos de energía» (Discorsi sopra la prima deca di Tito Livio, Obras completas, a cargo de Mario Martelli, Sansoni Editore, Florencia, 1992, p. 149/pp. 298-299).

43 Ibidem, p. 463.

44 Ibidem, p. 468.

45 La expresión es de Robert Derathé en las notas de su edición del Contrato Social (op. cit., p. 1504). Pero Derathé parece considerar esta integración de lo político en los dominios de lo sagrado como una especie de accidente: «Cabe la tentación de ver en ello una singular confusión de lo profano y de lo sagrado» (ibídem). Creo, por el contrario, que ése es un punto central de la filosofía política de Rousseau. 


\section{3. ¿Cómo desembarazarse de lo teológico-político?}

Creo que es preciso acometer una crítica radical de toda teología política: liberar la política de lo teológico y liberar lo teológico de lo político. Por tanto, aquí la crítica no debe entenderse en sentido kantiano porque no se puede definir una esfera propia de legitimidad de lo teológico-político. No se trata, pues, de trazar un límite en el seno del cual lo teológico-político podría ejercerse válidamente y más allá del cual se convertiría en fuente de ensoñaciones. Es preciso, al contrario, demostrar la invalidez del propio concepto, sea cual sea la historia secular que parece darle consistencia desde la Antigüedad y, más concretamente, desde san Agustín. En suma, hay que destruir lo teológico-político.

En el plano de los conceptos políticos, este proceso debe consistir en desacralizar de manera radical lo político reduciéndolo a su relatividad, su historicidad y su precariedad. En efecto, nada me parece más peligroso que la sacralización o la absolutización de lo político: conduce a la dictadura, a las guerras sin fin, a las luchas a muerte, a negarle todo valor a la individualidad humana, etc. Desacralizar los conceptos políticos significa reconstruirlos de tal forma que no sigan albergando contenidos o simples restos teológicos. $\mathrm{La}$ teología-política de Schmitt estaba fundada sobre restos teológicos remanentes, restos reconstruidos, reanimados. Para destruir lo teológico-político, conviene eliminar esos restos, reconstruir los conceptos políticos de tal forma que no guarden el tenor que podían tener en la Edad Media o incluso en la época moderna. Intentaré esbozarlo aquí respecto a dos conceptos primordiales: democracia y soberanía.

Para demostrar la posibilidad de esa desacralización de lo político, pondré un ejemplo que podría parecer paradójico: el del pensamiento de la democracia y de la soberanía del pueblo en Tocqueville. Este ejemplo puede parecer, en efecto, doblemente paradójico: en primer lugar porque es bien conocida la lectura casi teológica que Tocqueville hace, al principio de La democracia en América, del advenimiento de la democracia; y en segundo lugar, porque ya conocemos el papel que desempeña la religión en Estados Unidos y sobre el que Tocqueville insiste mucho. Pero esta doble paradoja sólo es aparente: es importante proceder a una disociación radical entre lo teológico-político, por una parte, y la religión por la otra. Es decir, debemos poder denunciar radicalmente la idea de que la política está necesariamente insertada en una estructura teológica sin, por ejemplo, cuestionar en modo alguno la importancia de la religión en la sociedad democrática. Ahora bien, por una parte, la teoría de la democracia no está dominada en Tocqueville por una estructura teológica y, por la otra, el recurso a consideraciones sociopolíticas sobre la religión no implica en modo alguno una sacralización de lo político. Sin duda es en Tocqueville donde podemos encontrar, en el marco de su conceptualización de la experiencia americana, uno de los esfuerzos más decisi- 
vos de reconstrucción no teológica de algunos de los conceptos claves de la época contemporánea.

Sobre el primer punto, se puede afirmar que ni en la definición social, ni en su definición política, la democracia está dominada por una estructura teológica en Tocqueville. El análisis de las formas de la democracia está vinculado a un análisis de sus patologías: las tendencias internas que la democracia porta en sí y que la llevan a su destrucción o a su negación en una forma nueva y particularmente moderna del despotismo. Pero sobre todo, si el concepto central de la definición de democracia política es la noción de «soberanía del pueblo», ésta ha perdido su sentido rousseauniano. La soberanía del pueblo en Tocqueville ya no es la transposición al pueblo de la soberanía que antes era atributo del rey y que, después de esa transferencia al pueblo, mantenía el mismo carácter sagrado. Ya no es una soberanía desde lo alto, voluntad a la vez trascendente e inmanente, dominando el cuerpo social y gobernándolo según una dirección única, sino soberanía desde abajo que asciende a partir de la forma más elemental de sociedad (la comuna) hasta la forma más compleja de institución política, a saber, una federación de Estados. Lo que implica en adelante que la soberanía es divisible, que puede ejercerse directa o indirectamente (por medio de representantes), que es susceptible de corromperse y transformarse en tiranía al menor descuido. Por tanto el concepto de soberanía política se emancipa completamente del modelo teológico que en un principio le había servido de modelo: la potentia absoluta dei. La soberanía es relativizada, reducida a una existencia histórica y factual, y la democracia que permite concebir es un régimen real que se inventa a sí mismo en la historicidad.

Esto no implica en modo alguno una especie de absolutización implícita y no dicha de la historicidad, como si no hubiese nada por encima de ésta, como si en adelante fuese preciso abandonarse al juicio de la historia $\mathrm{o}$, lo que viene a ser lo mismo, convertir a la historia en un nuevo Dios. La historización de la democracia, la relativización de la soberanía pueden y deben ser juzgadas según unos principios que nos remiten al derecho, a la libertad, a la humanidad, etc. Esta dimensión instaura una nueva tarea: la de construir unas normas y unos principios racionales de la política en un plano estrictamente antropo-jurídico-político.

En cuanto al segundo punto, las consideraciones sociopolíticas de Tocqueville sobre la religión no implican teologización o sacralización alguna, ni siquiera implícita, de lo político. Incluso cabe decir que son las únicas que legítimamente se pueden dar para tomar en consideración la importancia del fenómeno religioso en democracia. Consisten en mostrar: 1) que la religión desempeña un papel sociopolítico indispensable en la democracia, en la medida que constituye uno de los factores preponderantes para el mantenimiento del vínculo social y, como tal, sirve de contrapeso al individualismo; 2) dado que la democracia es una organización social y un régimen político que funciona 
como una espiral sin fin, donde los individuos son guiados por el deseo dominante de alcanzar su bienestar personal, la religión aparece como un factor susceptible de reintroducir una dimensión espiritual de significación y de finalidad más allá de un mundo material totalmente desencantado; 3) por último, la religión es modificada desde dentro, en sus dogmas y sus prácticas, por la sociedad democrática. Debe, en efecto, adaptarse a las disposiciones antropológicas de unos individuos que se piensan a sí mismos como seres autónomos y soportan a duras penas todo lo que viene a contradecir sus libertades personales, ya sean prácticas litúrgicas demasiado apremiantes o dogmas cuya autoridad reposa únicamente en la tradición.

Así vemos que la crítica de la sacralización de lo político bajo la figura de lo teológico-político no implica en modo alguno ignorar o desdeñar el fenómeno religioso.

\section{Conclusión}

La crítica radical de toda teología política, cuyo marco acabo de esbozar aquí y que intentaré llevar hasta el final en otro momento, aboga en cierta forma por el fin de la historia política de Dios. Este proyecto es aún bastante utópico hoy día, como si a los tiempos posmodernos en que hemos entrado le costase incluso más que a los tiempos modernos separar lo político de lo teológico, contrariamente a lo que preveían algunos apóstoles, ya desfasados, del desencanto y el fin de la religión.

Sin duda el programa de esta crítica supone, por una parte, reconstruir los conceptos fundamentales de la política suprimiendo el remanente teológico que su significación y su uso anterior pueden comportar aún y construir unos nuevos. Esto implica que esos conceptos deben ser reformulados enteramente. No se puede suprimir la huella del origen teológico en un concepto y dejarlo indemne. Esta crítica supone, por una parte, elaborar una teoría de las normas y de los principios que permiten evaluar y juzgar lo político (las instituciones y las prácticas de gobierno) evitando así el doble escollo de convertir a la historia en la instancia última de juicio o el de reintroducir subrepticiamente lo teológico a nivel de las normas. Es una vía muy ardua, pero también prioritaria. De su éxito o de su fracaso depende tal vez la forma del mundo político de mañana. 